\title{
Independent Study Logs: Guiding and Encouraging Students in the Process of Language Learning
}

\author{
Mary Frances Litzler \\ Department of Modern Philology, University of Alcala, Alcala de Henares, Spain
}

\begin{abstract}
Many people in Spain are studying English in order to find jobs in this country or to migrate as a result of the economic crisis. Language classes, however, are limited in duration and are often not enough to enable students to progress as much as they would like to. Language learners have to spend a considerable amount of time out of class studying and using English in order to get the most out of their class and to continue learning when classes are not in session. This article explains the use of independent study logs to guide and encourage learners in their language learning process during the period in which they attend class with a view towards their becoming more autonomous afterwards. The learners record the activities they do outside the classroom to learn and practice English along with any reactions they have in doing so and, in this way, the instructor can provide weekly or bimonthly feedback on their language learning strategies so that the experience can be more positive and more productive. This paper discusses the process followed along with student and instructor reactions to it, many of which are positive, as well as further applications for the use of independent study logs.
\end{abstract}

Index Terms—diary studies, learner autonomy, EFL, motivation, learning strategies

\section{INTRODUCTION}

Knowledge of English is now more important than ever in Spain due to the economic situation. Many young people are leaving the country to find work and others need it to obtain jobs within the country. As a result, many people are studying English and need to devote a number of years to acquiring a high level in the language. Language classes, however, are limited in duration and are often not enough to enable students to progress as much as they would like to. Language learners have to spend considerable time out of class studying and using English in order to get the most out of their classes, and there are down times when classes are not in session. This idea follows the thinking of Gabrielson (1990), who stated that "within the 600 to 700 hours of teaching that we have in school what we can hope to do is get them started" (p. 4). Some students seem to have a natural ability to know what they need but others require more guidance as is reflected in the literature on learner autonomy and different teaching approaches (Smith, 2003, p. 140ff; 2008, p. 396). Even those students who feel they know what they are doing often appreciate tips and encouragement from time to time. The guidance, tips and encouragement gained while taking a course in a classroom situation can help students in their independent study after class and during periods when classes are not in session.

This paper explains a method used to monitor students' work with English outside class with a view towards guiding and encouraging them in their autonomy for learning the language. It involves the students' writing logs with information on their independent study of English. Some background information on diary studies will first be presented. This information will be followed by a description of the classes in which this method has been used and an explanation of the actual procedure adopted, along with information on reactions encountered and some suggestions for further applications of the method to other learning situations.

\section{MAIN Body}

\section{A. Diary Studies}

Diary studies related to the learning of second or foreign languages have been described in a number of articles since the 1990s. Some studies are done by the researcher as a language learner, while others are done by language learners for a separate person acting as the researcher (see Curtis \& Bailey, 2009, for a list of both types of studies). In writing language learning diaries, learners write information and reflections on different aspects of their learning, such as their reactions to a class and the methodology used (Ruso, 2007; Christensen, Lindum, Orten, Rigbolt \& Vera-Batista, 1990; Dam \& Thomson, 1990), what activities they have done to learn English outside class (Halbach, 2000; Hyland, 2004), or other aspects of the learning experience related to a specific university course (Huang, 2005; Debreli, 2011). In terms of the actual content, Bailey \& Ochsner (1983) indicate in their review of diary studies that diarists should describe their language learning experience and "systematically record events, details, and feelings" (p. 189). Numerous studies follow this guideline but they often add their own twist to the data that should be recorded depending on their objectives. 
For instance, Hyland (2004) adds the idea of including "exposure to English" in addition to "use" of the language in a study on learner autonomy (p. 185), while Halbach (2000) focuses on the recording of problems and how they are followed up in an attempt at having students learn to solve their own language-learning difficulties (p. 87).

Studies involving diaries often involve writing prose entries in a journal for a period of a full semester or full year of study as part of a university course (for example, Debreli, 2011, p. 62; Ruso, 2007), but the period can be as short as one week (Hyland, 2004, p. 185). Mention is made of a requirement that entries should be "at least one page" (Hyland, 2004 , p. 185), or students are assigned exercises that require a fair amount of writing, such as "recording their conceptualization of EFL reading processes and their reflections on other aspects of EFL learning (e.g. listening, speaking, writing, grammar and vocabulary learning)" (Huang, 2005, p. 611). Because diaries are not specifically used as a language-learning activity but are instead intended to obtain information, most authors show no preference for the language in which they are written, be it the students' native language or English (for example, Rubin, 2003, p. 12; Matsumoto, 1987, p. 20; Curtis \& Bailey, 2009, p. 72). In fact, diary studies have been conducted successfully with English language learners in a variety of countries including Hong Kong (Hyland, 2004), China (Huang, 2005) and Turkey (Debreli, 2011). As will be seen below, the present study involves shorter entries for an intermediate length of time but the contents are similar to the above studies.

\section{B. Classes and Procedure}

Use of logs for this study started as part of a month-long intensive training course at the A2 level of the CEFR (Language Policy Unit) for secondary school teachers who must demonstrate a C1 level of English in order to qualify to teach their areas of specialization (not English) in a bilingual program in the Madrid region of Spain. The teachers attended the course for four hours per day for five days a week during the month of July (80 hours), and they were expected to do an average of two hours of homework per day throughout the month (20 hours). Many of them had not studied English for a number of years and they felt insecure about their ability to achieve the longer-term objective. In addition, they felt a threat of being moved to a different high school after numerous years at their current place of work if they did not reach the objective by the time their school applied for bilingual status.

In order to assist these teachers in their language learning process during the course and in preparation for a longer period of study with or without formal classroom instruction, some ideas about second language acquisition and the learning of a foreign language were explained to the group. Specifically, the importance of balancing study of grammar, vocabulary and pronunciation rules along with actual use of the language through reading, writing, listening and speaking was stressed. The instructor also devised a system for the teachers to record their work outside class in order to be able to advise them throughout the month. To do so, the teachers received a worksheet with a full-page chart for logging information on a number of factors: the date, the time their study started and the time it finished, the activities done with English, and their reaction to the work done (see Table 1 below). An emphasis was placed on brevity in their logs as opposed to lengthy prose diary entries, as noted above, in order to save them time and to enable them to concentrate on their homework. They were not instructed as to which language they should use, but all of them opted for English in order to practice the language. Any contact with English including watching TV in the target language, reading books, conversing with another person in the language or doing exercises from the book or other activities with the language could be recorded in the logs.

TABLE 1

SAMPLE LOG ENTRY PROVIDED TO STUDENTS AS PART OF THEIR INSTRUCTIONS

\begin{tabular}{|l|l|l|l|}
\hline Date & $\begin{array}{l}\text { Start time, } \\
\text { finish time }\end{array}$ & Activities & My reaction \\
\hline July 1 & $5.00-5.45$ & $\begin{array}{l}\text { Looked at the book, read lesson 1A and 1B, did workbook } \\
\text { 1A and1B, bought a notebook and wrote in my journal }\end{array}$ & $\begin{array}{l}\text { I am happy to be studying English. I understand } \\
\text { lesson 1A but lesson 1B is difficult for me. }\end{array}$ \\
\hline
\end{tabular}

The procedure for completing the logs was explained on the first day of class and the teachers were instructed to fill them in each day during the week after studying. The information was collected each Friday during the month and returned to them with written feedback the following Monday so that they could continue working in the same way for the next week.

The teachers' informal responses to the log activity at the end of the month were overwhelmingly positive because, they claimed, they had felt guided and encouraged by the instructor on how to proceed in studying. Thanks to this positive response, the log activity has been continued with other groups of students who need to achieve a high level of English for work reasons. Two groups in particular were primary school teacher trainees at a local university with levels ranging from $\mathrm{A} 2$ to $\mathrm{B} 2$ on the CEFR and translator trainees at the same university whose levels ranged from $\mathrm{A} 2$ to $\mathrm{C} 1$. In all of these cases the same procedure was followed, except that the format of the activity was less fixed. The students were not given a chart to fill in but were instead shown an example that they could follow similar to the above table. In these two classes the logs were collected every two weeks during a period of 8 weeks. Many of the teacher trainees opted to use English to fill in their logs but a few of them preferred to use Spanish. The translator trainees, however, all used English to do them. At present logs are being used by another two groups of C1.1 level students at a private language school for adults. In this case the format is completely free and the students do them on a voluntary basis, 
submitting them every two weeks as long as they are interested in continuing the activity. They are writing the logs in English out of their own choice.

When revising the logs, the instructor looks at a number of aspects. The first is how often and how long the students study as they are encouraged to attempt frequent albeit shorter periods of contact with the language as opposed to longer, intense study sessions only once or twice per week. Students who work only one day a week for several hours receive written feedback encouraging them to try to seek out 2-3 days, if not 4 days, but a shorter amount of time. The time that the students study English is also very revealing as it sometimes becomes clear that their family, study and/or work obligations mean that they can only study late at night, an additional constraint on their learning. The next aspect examined in the logs is the different activities that they do to make progress with the language. It is here that it is seen if they are balancing traditional-type study of the building blocks of the language along with practice in using the language. When they focus too much on one area or another and depending on their ability and personality in the classroom, they receive written advice from the instructor in their logs in order to help them find ways to reinforce the aspect of learning that needs to be improved. For example, one of the teacher trainees who watched basketball games in English frequently but who never practiced reading was encouraged to look for newspaper articles about the matches that he had seen on TV. Another student at the C1.1 level who was having difficulty in general with the course and was practicing conversation with a private tutor was encouraged to examine the method used: "Does your tutor correct certain mistakes? Or is there no pattern? If he/she can focus on $\mathrm{S}+\mathrm{V}+\mathrm{O}$ word order and verb tenses (or another typical mistake) it may help you focus more." This student had a particular problem in these areas but was unable to complete the course in the end.

The last part of the log observed is actually the most important: the reaction of the students to what they are doing. By observing the students' logs over time, patterns of enthusiasm, optimism, frustration and negativity appear. If students seem positive, this attitude is reinforced as much as possible through written feedback, such as "I am happy that you feel this way," or "excellent." In the cases in which they appear to be frustrated or negative regarding their learning, the instructor attempts to encourage them to study in other ways to prevent boredom or frustration and to find ways that could be more rewarding. A typical comment might be "This is normal. Don't worry. Give yourself time." Others are "Try to concentrate on what you understand at this point," or "Be patient with yourself." The students find that these individual comments are helpful and are encouraged, especially in the context of a fast classroom routine with little time for individualized attention in person. Nevertheless, the logs are also used to suggest that students talk to the instructor.

\section{Reactions Encountered}

A number of difficulties related to the students' working with logs have been observed on the various occasions in which they have been used. A first one is, obviously, that learners can invent the information, particularly when they are in a university setting and are doing the log as part of their mark; no measures have been taken to attempt to verify the information, but the students themselves have recognized this possibility, as evidenced in a teacher trainee comment in a post-activity survey: "I think that in many cases people invent the things but didn't do them" (author translation from Spanish). Another problem is that students forget to write down their activities on a daily basis and, hence, are forced to fill them in the day that they are submitted to the instructor; the nature of the log activity requires a certain degree of discipline on the part of learners, as inferred by one of them: "Bearing in mind that I am not organized, keeping the log was tedious as well as boring. I don't like to have to pay attention all the time to how long it takes me to do something." As a result, the logs are often hastily done and the information is quite possibly less accurate than if they were to record it immediately after doing it. Again, this is evidenced in the students' post-activity surveys: "Sometimes I found it boring because I don't write the things that I do in the same day and I've to do it all in the same day." The solution in these cases is to reinforce the utility of the log exercise and the need for accurate information.

The remaining difficulties encountered are related to the actual filling in of the forms. For example, the students sometimes fill in only a small amount of information about their activities, such as "homework" or "I do the exercises." If they simply report that they have studied from the book, but it cannot be determined what kind of work has been done or what aspect of English it is related to, some individual in-person consultation can clarify the situation so that feedback can be provided. Another common difficulty found is that learners often leave the part of their reaction out of the log the first times that it is submitted. They appear to be confused about the nature of this section and the original examples provided do not appear to be enough. A next stage observed in their filling out this section is that they report facts such as how many questions they have done correctly out of the possible total, as in " 15 out of 20 correct," or We were speaking about all kinds of relationships between English and Spanish families." While these comments are interesting and valuable, the learners are encouraged to move to a more affective view of their work. After reinforcing the idea of this part of the log in their initial feedback and through group feedback during the class, students tend to understand the idea requested of them and start providing the information sought, for example, "I think I am learning what I learned in a bad way in the past" or "I'm happy because I understand the different futures."

Two final difficulties related to the way in which the learners fill out the logs have to do with the nature of the exercise in general. Some students show resistance to doing the logs due to time constraints. As the students had a particularly heavy workload during the semester in which they were completing the logs, some of them did not want to take the time to fill them in every day as evidenced by one person: "I don't have time to do exercises like this because 
the other subjects need a lot of time too, so in that way, writing the log at the end of the day is boring for me." A final problem is that sometimes students do not see the rationale for doing them. In the case of some of the translation students, they felt there was no need for them as they already knew how to learn English: "In my case doing the log has not been very useful, because I already know what I do to improve my English level. I don't need a paper to know that." A clear explanation of the purpose of the logs at the start of the activity can help mitigate some of this resistance; doing the logs on a voluntary basis may also help.

A last potential problem concerns the teacher or instructor who collects the logs from the learners and provides feedback. Obviously, this process takes time. An average of thirty to forty minutes is required to read and provide feedback for a group of 25-30 students on a bimonthly basis. This investment in time has repeatedly proved to be worth the effort in light of the number of students' informal positive responses and the increased rapport observed in classes that do logs compared to classes that do not.

In fact, learners tend to be more positive in post-activity surveys than negative about the logs, despite the problems reported above (Litzler, unpublished). They directly and/or indirectly describe the logs as being a motivating factor in their studies when asked to report on them. Some of the aspects of motivation mentioned include their being able to see more clearly their own effort and realizing how much they have done to make progress, appreciation for the individualized feedback provided by the instructor, and their feeling that they need to make a greater effort in the class. The novelty of the exercise was also highlighted by many of the students. They had been studying English for many years in primary and secondary school before attending university but had never been asked to report on what they had done outside class, nor had they been encouraged to look for alternative ways to practice use of the language. Many students also highlighted the fact that the logs also helped them organize their work, as evidenced in such survey comments as: "Using the log I can organize the work I do with English, what I am doing from week to week, what is more difficult, what I have learned and, above all, what I have improved so I think it has been a great idea" (author translation from Spanish). Finally, in an open question, C1.1 level students who did logs on a voluntary basis one time only described the logs as "useful" for a variety of reasons.

\section{Further Applications}

As mentioned above, the logs described in this study have been used with secondary school teachers and university students. In all of these cases the logs were completed with a view towards the instructor's providing feedback on the students' organization of time and their activities to learn and improve their English level. The logs were filled out on a daily basis and submitted to the instructor every week or every two weeks for a maximum of 8 weeks as part of their course requirements. In recent months they have also been recommended to C1.1 level students attending English classes at a private language school on a voluntary basis. Nevertheless, the use of logs can be applied to other situations. Obviously, they can be used for longer or shorter periods of time, they can be filled out less often, and they can be collected more or less frequently, depending on the students' needs and the teacher's availability. However, they can also have other applications, such as the tracking of students' use of multiple intelligences, monitoring of their use of new technologies in independent-study, or even encouragement of positive affective conditions to favor autonomous learning. The fact that diary studies have been successful in other countries such as Hong Kong (Hyland, 2004), China (Huang, 2005) and Turkey (Debreli, 2011) means that their positive application beyond Spain is feasible too. These are just a few ideas of many other possibilities depending on the class characteristics and teachers' individual focuses. The format, initial student orientation, and type of teacher feedback provided can be adapted to the needs and focus of the class and culture in question.

\section{CONCLUSION}

This experience with using independent study logs to guide and encourage secondary school teachers and university students in their learning of English outside an English class has varied from other studies using diaries in that it required brief entries for an intermediate period of time ( 8 weeks), as opposed to longer prose entries for an entire semester of study. Nevertheless, the contents of the logs tended to follow that of other successful studies reported for different experiences in other countries and required recording of each date, time of study, the activities done each time and any reactions to the activities. Overall, the experience has proved to be positive for both the instructor and the learners involved as the activity appears to help the students. The learners tended to appreciate the instructor's individual written feedback about their selection of activities for study and they also found that doing the log helped them in other ways such as organizing their time and seeing the effort they were putting in to learning the language. Use of the logs also seems to generate a higher level of rapport for everyone involved. On the occasions that some students were resistant, it can be deduced that the rationale behind the activity needs to be better explained.

Future work with logs can focus more specifically on their use on a voluntary basis at different levels. It can also examine their applicability to monitoring different factors of language learning such as development of multiple intelligences, use of new technologies for language learning, and positive affective conditions for autonomous learning. 


\section{REFERENCES}

[1] Bailey, K. M. \& R. Ochsner. (1983). A methodological review of the diary studies: Windmill tilting or social science? In K. M. Bailey, M.H. Long, \& S. Peck (eds.), Second language acquisition studies. Rowley, MA: Newbury House, 188-198.

[2] Christensen, A. L., A. Lindum, P. Orten, U. Rigbolt, \& J.L. Vera-Batista. (1990). The use of diaries and case studies. In T. Trebbi (ed.), Third Nordic workshop on developing autonomous learning in the FL classroom, Bergen, August 11-14, 1989. Bergen: Universitet I Bergen: Institutt for praktisk pedagogikk, $103-107$. http://www2.warwick.ac.uk/fac/soc/al/research/groups/ellta/circal/dahla/archive/trebbi-1990.pdf (accessed 7/1/2014).

[3] Curtis, A. \& K. M. Bailey. (2009). Diary studies. OnCUE Journal 3.1, 67-85. http://jaltcue.org/files/OnCUE/OCJ3-1articles/OCJ3-1-Curtis-Bailey-pp67-85.pdf (accessed 27/1/2014).

[4] Dam, L. \& H. Thomsen. (1990). Learning how to learn: Awareness in the classroom and in workshops. In T. Trebbi (ed.), Third Nordic workshop on developing autonomous learning in the FL classroom, Bergen, August 11-14, 1989. Bergen: $\begin{array}{lllll}\text { Universitet I } & \text { Bergen: for pratitt }\end{array}$ http://www2.warwick.ac.uk/fac/soc/al/research/groups/ellta/circal/dahla/archive/trebbi-1990.pdf (accessed 7/1/2014).

[5] Debreli, E. (2011). Use of diaries to investigate and track pre-service teachers' beliefs about teaching and learning English as a foreign language throughout a pre-service training Program. Procedia: Social and Behavioral Sciences 15, 60-65. www.sciencedirect.com (accessed 28/1/2014). doi: 10.1016/j.sbspro.2011.03.051.

[6] Gabrielsen, G. (1990). Basic concepts and current issues. In T. Trebbi (ed.), Third Nordic workshop on developing autonomous learning in the FL classroom, Bergen, August 11-14, 1989. Bergen: Universitet I Bergen: Institutt for praktisk pedagogikk, 3-8. http://www2.warwick.ac.uk/fac/soc/al/research/groups/ellta/circal/dahla/archive/trebbi-1990.pdf (accessed 7/1/2014).

[7] Halbach, A. (2000). Finding out about students' learning strategies by looking at their diaries: A case study. System 28, 85-96. www.elsevier.com/locate/system (accessed 27/1/2014).

[8] Huang, J. (2005). A diary study of difficulties and constraints in EFL learning. System 33, 609-621. www.elsevier.com/locate/system (accessed 27/1/2014). doi: 10.1016/j.system.2005.04.001.

[9] Hyland, F. (2004). Learning autonomously: Contextualising out-of-class English language learning. Language Awareness 13.3, 180-202.

[10] Language Policy Unit, Common European framework of reference of languages: Learning, teaching, assessment. Strasbourg: Council of Europe. www.coe.int/lang-CEFR (accessed 15/2/2014).

[11] Litzler. (unpublished). Survey results of student satisfaction with using independent study logs as part of English classes.

[12] Matsumoto, K. (1987). Diary studies of second language acquisition: A critical overview. JALT 9, 17-34. http://jalt-publications.org/jj/articles/2833-diary-studies-second-language-acquisition-critical-overview (accessed 27/1/2014).

[13] Rubin, J. (2003). Diary writing as a process: Simple, useful, powerful. Guidelines. 25.2, 10-14. http://www1.openedu.com.cn/elt/index21.htm (accessed 15/2/2014).

[14] Ruso, N. (2007). The influence of task based learning on EFL classrooms. Asian EFL Journal 18, 1-23. http://asian-efl-journal.com/pta_February_2007_nr.php (accessed 28/1/2014).

[15] Smith, R. (2003). Pedagogy for autonomy as (becoming-) appropriate methodology. In D. Palfreyman \& R. C. Smith (eds.), Autonomy across Cultures: Language Education Perspectives. Basingstoke: Palgrave Macmillan, 129-145.

[16] Smith, R. (2008). Learner Autonomy. ELT Journal 62.4, 395-397. www.eltoxfordjournals.org (accessed 3/1/2014). doi: $10.1093 /$ elt/ccn038.

Mary Frances Litzler holds a PhD in English from the University of Las Palmas de Gran Canaria in Spain since 2011 and an M.A. in applied linguistics from the University of Southern California, U.S.A., since 1987. She has more than 25 years' experience teaching university students and other adults. In recent years she has been teaching English at the British Council Foundation and English language, linguistics and translation at the University of Alcala, both of which are located in central Spain. Her research interests and publications relate to learner autonomy, student attitudes towards classroom methods, testing and new technologies. 